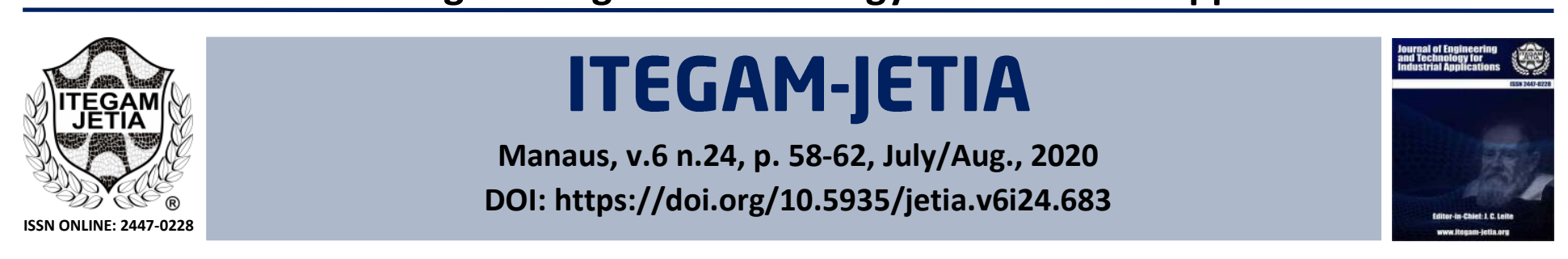

\title{
DESIGN PERFORMANCE OF LEAD AND LAG COMPENSATOR USING OPAMP AND ROOT LOCUS APPROACH THROUGH SIMULATION TOOL
}

\author{
Badri Narayan Mohapatra ${ }^{1}$ and Jijnyasa Joshi $^{2}$
}

${ }^{1,2}$ Department of Instrumentation \& Control of AISSMS IOIT, University of Savitribai Phule Pune University - SPPU. Pune, 411001, India.

\author{
${ }^{1}$ http://orcid.org/0000-0003-1906-9932 (10)
}

Email: badri1.mohapatra@gmail.com, aissmsiit@gmail.com

\section{ARTICLE INFO}

\section{Article History}

Received: August $01^{\text {th }}, 2020$

Accepted: August 13 $3^{\text {th }}, 2020$

Published: August $31^{\text {th }}, 2020$

\section{Keywords:}

Compensator,

Root locus,

Tinkercad,

Lead,

Lag network.

\begin{abstract}
The design objective behind lead and lag compensator is to meet the relative stability as well as to meet desired performance. Both in time domain or frequency domain, the compensator design can be carried out. Absolute stability of a system can be predicted from root locus approach. Simulation tool like tinkercad and wolfram alpha can provide easy access of different control engineering design performance, so that it helps all under graduate, post graduate and researchers can able to apply their knowledge to engineering application from any computing environment. And they can perform it at any time. By this passive learning is also possible with active engagement in the learning related to practical and theory. To judgment and easily understand on simulation, student can modify their design specification and get deeper knowledge on control system design engineering. one can also use opamp circuit to understand the compensator design performance.
\end{abstract}

Copyright (C2016 by authors and Galileo Institute of Technology and Education of the Amazon (ITEGAM). This work is licensed under the Creative Commons Attribution International License (CC BY 4.0).

\section{INTRODUCTION}

Now a day's learning and designs can be enhanced through interactive tool. Due to personal computer and especially smart mobile phone can make it possible to solve sophisticated control system problems with easy, simple and concise manner. Level of competences increase only when students will go for practice. Design and tuning by adding different pole and zero parameter to the system, stability can be increases as per required performance. The basic principle should necessary to remember for all engineering students. Different computing tool can help students and instructor to teach and learn process due to covid19 pandemic situation. Basic opamp circuit is used for lead and lag compensator [1]. The main aim of the research behind is that the importance of pole position and its effect is important, as one of the researcher have already find the control of helicopter model [2]. Different virtual laboratory are there for easily the experiment can be carried out for system designing, implementing and controlling [3]. Laboratory experiments play a vital role in control system design, theory to apply in design concept which is more important [4]. The fundamental concept can be understand by basic text book of control system design [5], automatic control system [6] and control system engineering [7].

\section{LEAD AND LAG OPAMP CIRCUIT}

Many parameters involved in the real world and different parameter involve with physical quantity and all things can be represented in mathematical model. From many decades opamp have been used for many applications. Many popular text book treat different work concept with variety of application. There are lot of analog ckt tools available where one can easily implement the concept of opamp. Figure 1 and 3 are the respective lead and lag opamp circuit.

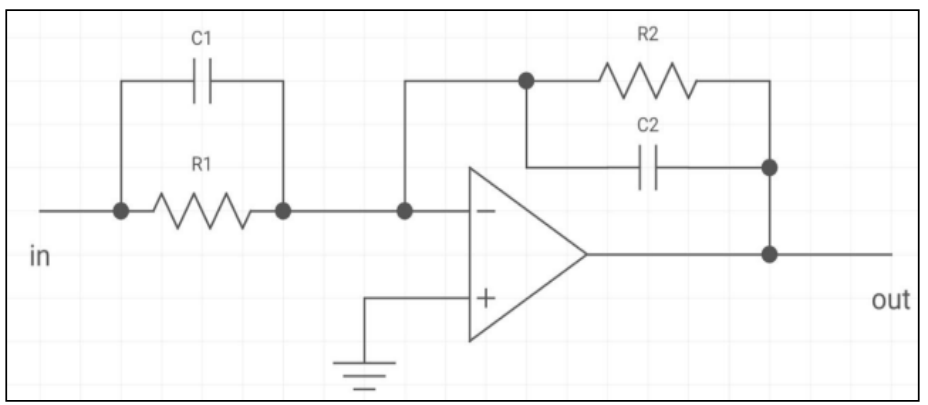

Figure 1: Lead Compensator (R1C1> R2C2). Source: Authors, (2020). 
For the concept of lead and lag here we are analyzing through tinkercad and wolfram tool. Connect opamp Ics (741) on the breadboard then take resistors $(\mathrm{R} 1=358$ Kilo ohms, $\mathrm{R} 2=179$ kilo ohms, ) and 4 capacitors $(\mathrm{C} 1=5.6$ micro farad, $\mathrm{C} 2=0.1$ micro farad for lead compensator design as $\mathrm{R} 1 \mathrm{C} 1$ should be greater than R2C2. similarly, R3=179 kilo ohms, R4=358 kilo ohms C3=0.1 micro farad, C4=5.6 micro farad for lag compensator. And connect them in parallel combination with each other (R1C1, $\mathrm{R} 2 \mathrm{C} 2$ for lead design and for lag compensator design take R3C3, $\mathrm{R} 4 \mathrm{C} 4)$.

Connect $\mathrm{R} 1 \mathrm{C} 1$ and $\mathrm{R} 3 \mathrm{C} 3$ combinations to the pin number 2 of the opamp ICs respectively such that one terminal of the parallel combination (of the resistor and capacitor) should be connected to the power supply and the $\mathrm{R} 2 \mathrm{C} 2$ and $\mathrm{R} 4 \mathrm{C} 4$ combination to the pin number 6 of the opamp ICs respectively so that they are grounded.

After that make ground the pin number 3 of both the opamp ICs and connect the pin number 4 of both opamp ICs to the power supply (-ve). Connect pin number 7 of both the opamp ICs to the power supply (+ve). Now connect pin number 2 with pin number 6 of both the opamp ICs. Now using a function generator provide power supply through the breadboard.

Connect power supply (+ve) to the breadboard (i.e. by connecting the positive terminal to positive end of the breadboard and negative terminal to the negative terminal of the breadboard).

8) Now connect other power supply (-ve) to the breadboard (i.e. by connecting the positive terminal to negative end of the breadboard and negative terminal to the positive terminal of the breadboard). Now connect oscilloscopes to two to the input and two for the output. For input, connect the positive terminal of the oscilloscope to the power supply on the breadboard and the negative terminal is to be grounded.

10) Now connect the remaining two oscilloscopes by connecting the positive terminal of the oscilloscope to the power supply on the breadboard and negative terminal is to be connected to the parallel combination of the resistor and capacitor ( $\mathrm{R} 2 \mathrm{C} 2$ and R4C4). Also interconnect the positive terminals of the breadboard and the negative terminals with each other (+ve to +ve and -ve to -ve). The simulation results for lead and lag circuit is carried out through tinkercad circuit tool [8].

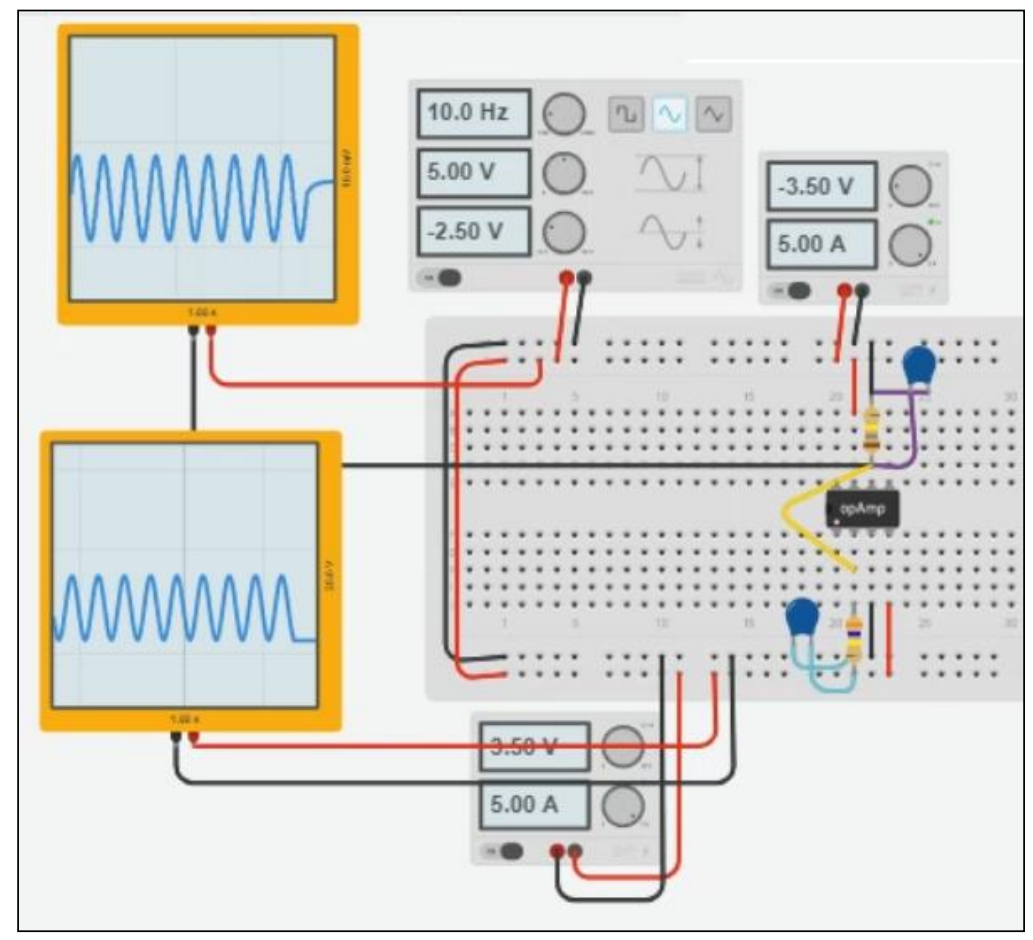

Figure 2: Lead Compensator using opamp circuit.

Source: Authors, (2020).

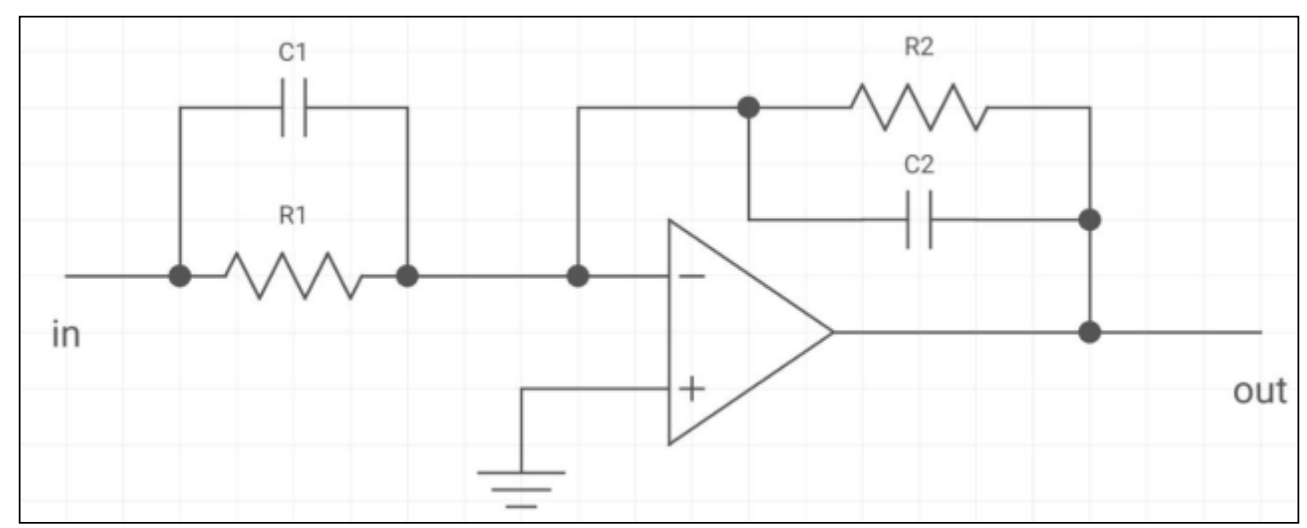

Figure 3: Lag Compensator (R1C1< R2C2).

Source: Authors, (2020). 
The effects of lead and lag compensator shows in oscilloscope Figure 2 and 4. Normally damping which will be more in case of led compensator. Due to this less rise time and less overshoot.

With the observation from oscilloscope one can easily find the lead and lag phase difference. Depending on the values of register and capacitor, the circuit behaves as lead and as well as lag. Any type of correction if a system will require then compensator circuit is very useful. Some cases lead lag compensator that is combination circuit is also useful. Satellite launching, automobile, robotic control its use is more.

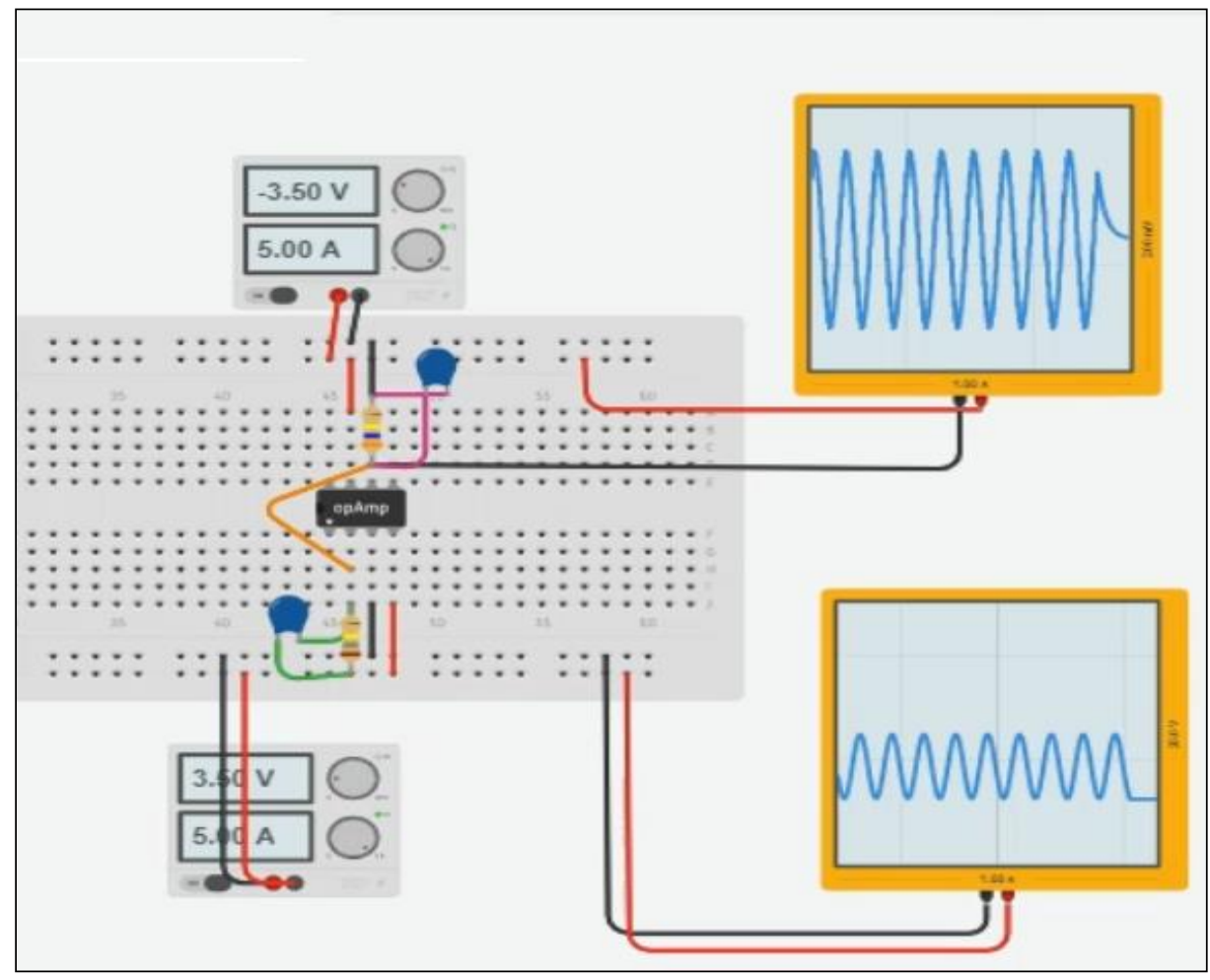

Figure 4: Lag Compensator using opamp circuit.

Source: Authors, (2020).

\section{ROOT LOCUS APPROACH}

A pair of pole-zero has to be form for realization of compensated network. If a network having pole nearer to imaginary axis then it introduces a lag network. In general compensating represented as:

Compensator network:

$$
G(s)=\frac{(\mathrm{s}+\mathrm{a})}{(\mathrm{s}+\mathrm{b})}
$$

If $a>b$ it's lag, if $a<b$ its lead

Consider a system:

$$
G(s)=\frac{100}{\mathrm{~s}(\mathrm{~s}+9)}
$$

Depend upon the value of value of zero and pole the compensator may lead type $(a<b)$ or lag type $(a>b)$.

Lead Compensator network:

$$
G(s) G_{c}=\frac{100}{s(s+9)} \frac{(s+10)}{(s+16)}
$$

Lag Compensator network:

$$
G(s) \cdot G_{c}=\frac{100}{s(s+9)} \frac{(\mathrm{s}+10)}{(\mathrm{s}+0.0016)}
$$

Here we are considering as an example of a system gain as per Equation 2 but for that system if someone will add a compensator network, then the output response in the root locus plot which will vary like close and away from the origin. The root locus of the main considered system is shown in Figure 5 but if lead network or lag compensator network will be introduced then the output is shown in Figure 6 and Figure7. The simulation result which was carried by the wolfram alpha tool [9].

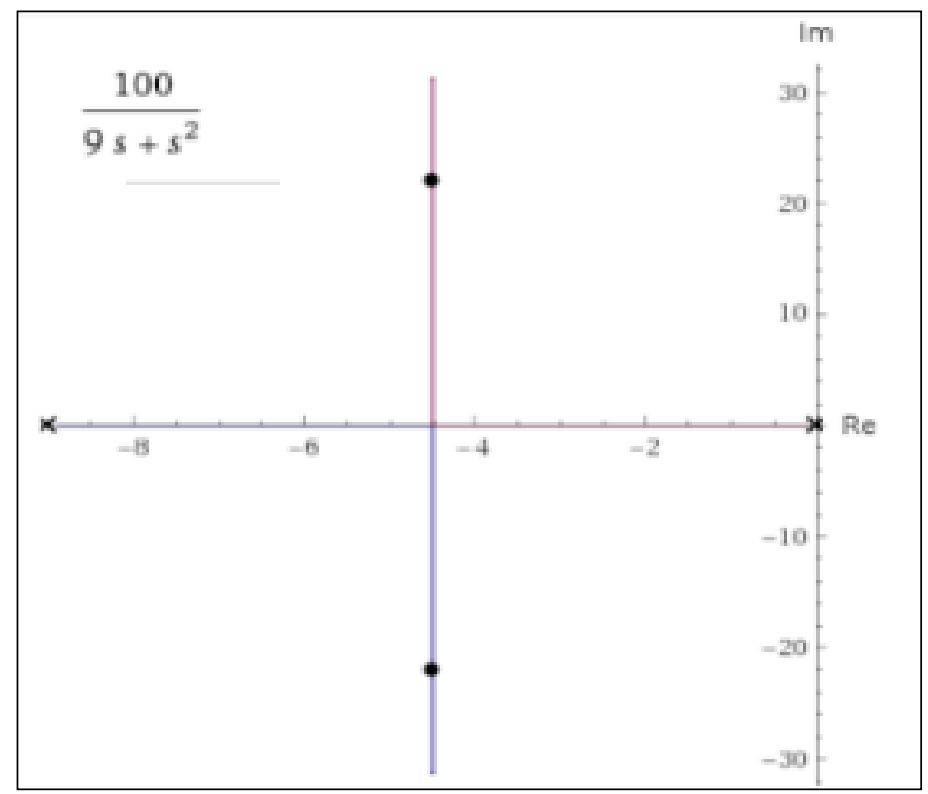

Figure 5: Root locus for uncompensated system. Source: Authors, (2020). 
As per the equation written in 1 , based on that one can say what type of compensator should be require for a system output performance. As from Figure 5 as it is in stable condition even after if someone will go for lag or lead then how the response change that can easily observable through root locus simulation.

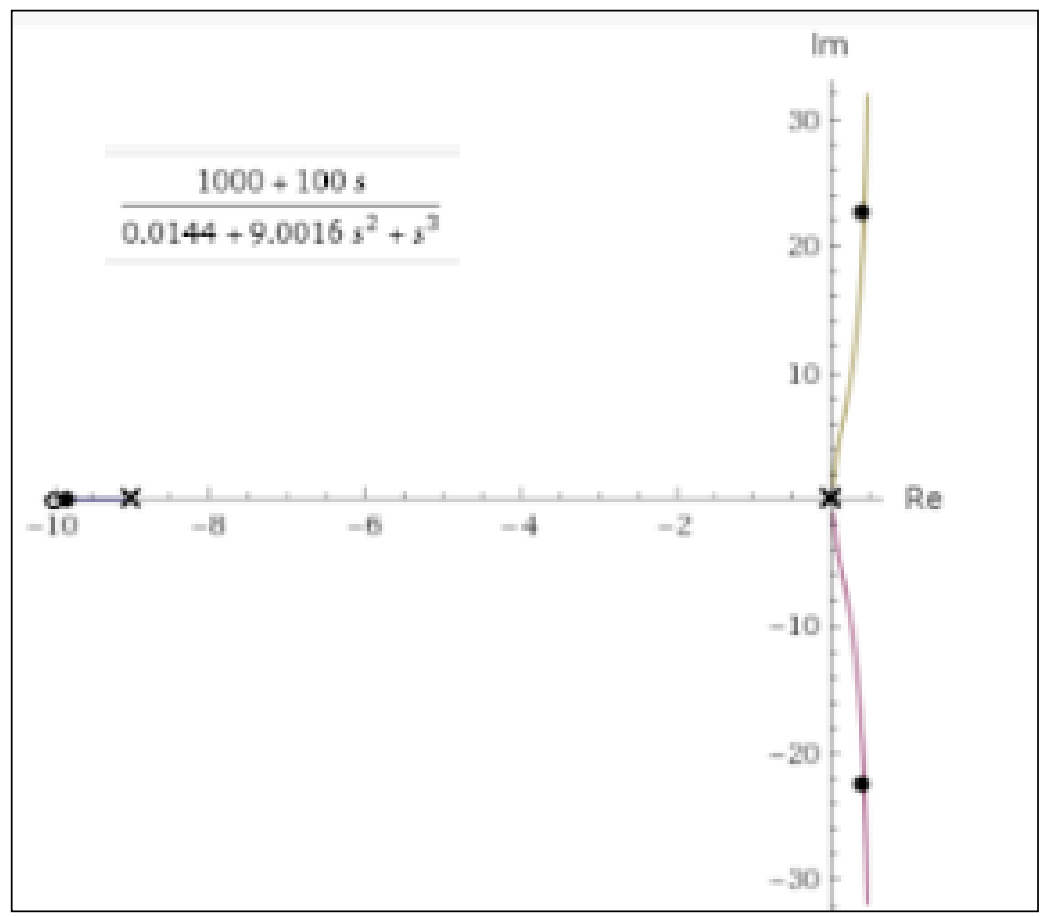

Figure 6: Root locus for lag network.

Source: Authors, (2020).

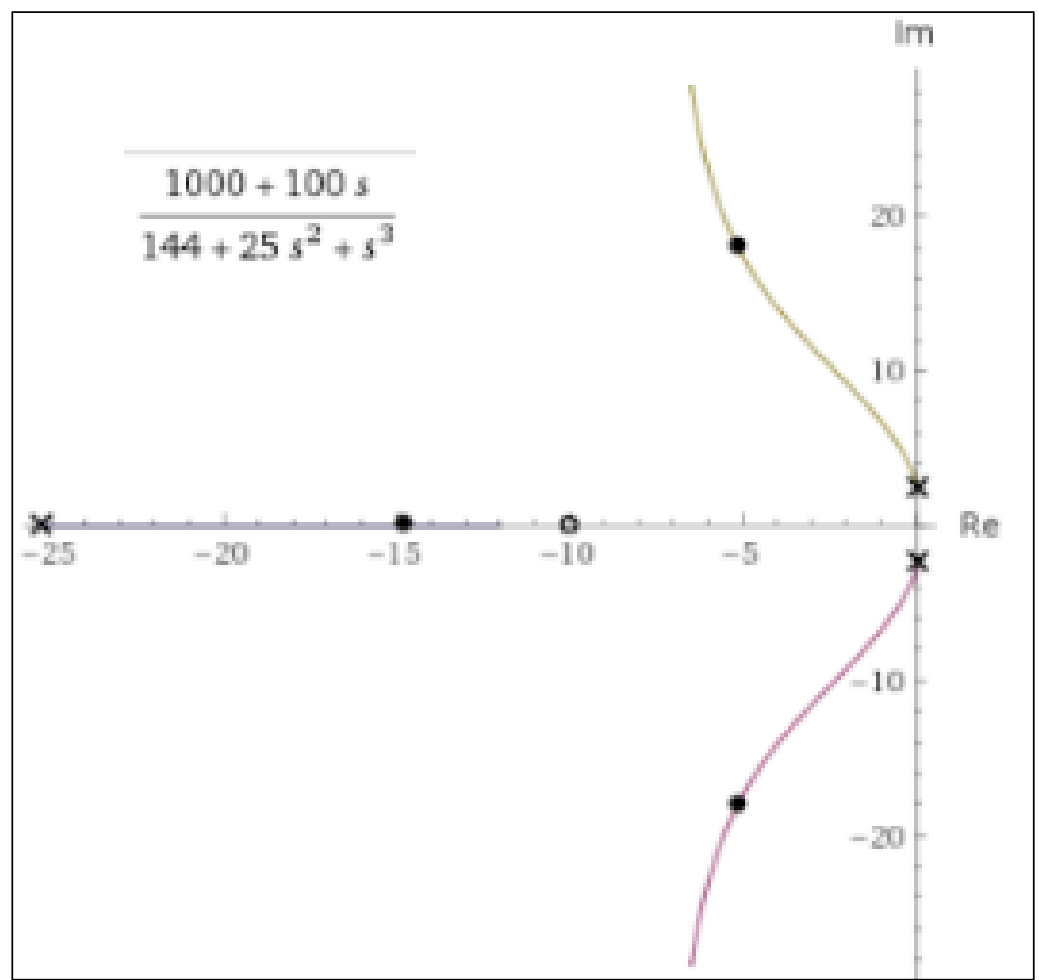

Figure 7: Root locus for lead network.

Source: Authors, (2020).

\section{CONCLUSIONS}

In this research result we can easily visualize the phase difference in oscilloscope by drag and drop of all require components to the breadboard and simple connection as per circuit connection by using tinkercad. Secondly, we can compare lead and lag by proper value choosing for compensator so that the root locus line, which will indicate the system stability using mathematical tool. This type of simple research may help students on lead and lag concept with analysis of mathematical model. Root locus and lead and lag compensator may help undergraduate students about the stability of the system. such type of 
computational tool can help students for their choice of different control by choosing by their own choice value and this way they can understand the problem and concept behind control theory.

To make students learn easily, effort has been expanded through web base tool. Many concepts can be analysis with fast and deep easily through interactive tool.

\section{ACKNOWLEDGMENTS}

I would like to thank AISSMS IOIT undergraduate student Jijnyasa who have completed on timely collection of compilation of results in the research work. I have appreciated her motivation towards this research.

\section{REFERENCES}

[1] C. Muñiz-Montero, L. A. Sánchez-Gaspariano, C. Sánchez-López, V. R. González-Díaz, and E. Tlelo-Cuautle, "On the Electronic Realizations of Fractional-Order Phase-Lead-Lag Compensators with OpAmps and FPAAs", Fractional Order Control and Synchronization of Chaotic Systems, pp. 131-164, 2017, doi: 10.1007/978-3-319-50249-6_5.

[2] "Items where Year is 2011 - UTHM Institutional Repository". http://eprints.uthm.edu.my/view/year/2011.html (accessed Aug. 01, 2020).

[3] V. Nagargoje and P. H. Bhagat, "Virtual laboratory of control system", 2017 International Conference on I-SMAC (IoT in Social, Mobile, Analytics and Cloud) (I-SMAC), 2017, doi: 10.1109/i-smac.2017.8058381.

[4] D. M. Ovalle and L. F. Combita, "Engaging Control Systems Students with a Pneumatic Levitator Project", 2019 IEEE Global Engineering Education Conference (EDUCON), 2019, doi: 10.1109/educon.2019.8725270.

[5] B. Manke S., Control System Design. Stylus Publishing, LLC, 2017.

[6] Kuo and Golnaraghi, AUTOMATIC CONTROL SYSTEMS, 8TH ED (With CD). John Wiley \& Sons, 2007.

[7] N. Nise S., Control Systems Engineering. 2011.

[8] "Learn how to use Tinkercad Circuits". https://www.tinkercad.com/learn/circuits (accessed Aug. 01, 2020).

[9] "Wolfram|Alpha: Computational Intelligence". https://www.wolframalpha.com/ (accessed Aug. 01, 2020). 